\title{
Stenting in the treatment of acute ischemic stroke: literature review
}

\section{Edgar A. Samaniego, Guilherme Dabus and Italo Linfante*}

Interventional Neuroradiology and Endovascular Neurosurgery, Baptist Cardiac and Vascular Institute, Miami, FL, USA

Edited by:

Shakir Husain Hakim, Max Institute of Neurosciences, India

\section{Reviewed by:}

Angelos A. Konstas, Massachusetts General Hospital, USA

Edgard Pereira, JFK Medical Center, USA

\section{*Correspondence:}

Italo Linfante, Interventional Neuroradiology and Endovascular Neurosurgery, Baptist Cardiac and Vascular Institute, $8900 \mathrm{~N}$ Kendall Drive, Miami, FL 33176, USA. e-mail: italol@baptisthealth.net
Recanalization of acute large artery occlusions is a strong predictor of good outcome. The development of thrombectomy devices resulted in a significant improvement in recanalization rates compared to thrombolytics alone. However, clinical trials and registries with these thrombectomy devices in acute ischemic stroke (AIS) have shown recanalization rates in the range of $40-81 \%$. The last decade has seen the development of nickel titanium self-expandable stents (SES). These stents, in contrast to balloon-mounted stents, allow better navigability and deployment in tortuous vessels and therefore are optimal for the cerebral circulation. SES were initially used for stent-assisted coil embolization of intracranial aneurysms and for treatment of intracranial stenosis. However, a few authors have recently reported feasibility of deployment of SES in AIS. The use of these devices yielded higher recanalization rates compared to traditional thrombectomy devices. Encouraged by these results, retrievable SES systems have been recently used in AIS. These devices offer the advantage of resheathing and retrieving of the stent even after full deployment. Some of these stents can also be detached in case permanent stent placement is needed. Retrievable SES are being used in Europe and currently tested in clinical trials in the United States. We review the recent literature in the use of stents for the treatment of AIS secondary to large vessel occlusion.

Keywords: self-expandable stents, acute ischemic stroke, enterprise, neuroform, solitaire, trevo, wingspan, stenting

\section{INTRODUCTION}

Recanalization is a strong predictor of good outcome in cerebral ischemia secondary to large vessel occlusion (Nogueira et al., 2009a). Recanalization rates with Food and Drug Administration (FDA) approved thrombectomy devices such as the Concentric Thrombus Retriever (Concentric Medical, Mountain View, CA, USA) and the Penumbra System (Penumbra Inc., Alameda, CA, USA) range between 40 and $81 \%$ (Flint et al., 2007).

In particular, pooled results of the mechanical embolus removal in cerebral ischemia (MERCI) and Multi MERCI Part I trials showed a $63 \%$ recanalization rate with the use of the Merci Retriever and adjunctive endovascular treatment (Flint et al., 2007). Good clinical outcomes (Modified Rankin Scale, $m R S \leq 2$ at 3 months) were observed in 39\% patients with ICA recanalization. The other FDA approved device for mechanical thrombectomy, the Penumbra System, showed an $81 \%$ recanalization rate (thrombolysis in myocardial infarction, TIMI 2/3; Penumbra Pivotal Stroke Trial Investigators, 2009). Good clinical outcome $(\mathrm{mRS} \leq 2$ at 3 months) was seen in $25 \%$ of patients. Unfortunately, recanalization rates with these devices are variable and some lesions like carotid terminus or basilar artery occlusions have a poor response to alternative therapies like thrombolytics (IMS Study Investigators, 2004). Furthermore, the Merci Retriever often requires frequent passes to achieve complete recanalization (Smith et al., 2005); while the Penumbra aspiration system generates clot fragments that may embolize distally (Gounis et al., 2010). Newer and better endovascular devices are needed to achieve better outcomes.
Balloon-mounted stents and later on, self-expandable stents (SES), have been used with increased success in large vessel recanalization during acute ischemic stroke (AIS). Moreover, retrievable SES systems like the Solitaire (ev3, Plymouth, MN, USA) and Trevo (Concentric Medical, Mountain View, CA, USA) offer the advantage of stent resheathing even after full deployment and detachment of the stent in cases where permanent stent placement is needed (Solitaire FB). In this review we analyze the evolution of stent technology for treatment of AIS.

\section{HISTORICAL PERSPECTIVE}

Phatouros et al. (1999) reported the first endovascular stenting of an acutely occluded basilar artery with excellent angiographic results. In their case report, after failure to recanalize the occluded vessel with intraarterial (IA) thrombolysis and balloon angioplasty, a balloon-mounted stent was successfully deployed resulting in TIMI-3 flow. Gupta et al. (2003) reported a series of 18 patients treated urgently with angioplasty and/or stenting due to impending stroke. Four patients in this series underwent stenting, although only two had acute strokes in diffusion weighted imaging. The overall rate of major periprocedural complications was 50\%. Levy et al. (2006a) treated 19 patients with AIS and achieved TIMI $2 / 3$ in $79 \%$ of cases. All the patients in this series failed different recanalization approaches, which included angioplasty, IA thrombolysis, and thrombectomy with a snare device. The rate of intracerebral hemorrhage was $5 \%$. All the stents used up to this point are coronary balloon-mounted stents. 


\section{SELF-EXPANDABLE INTRACRANIAL STENTS}

Self-expandable stents were approved for vessel remodeling in the treatment of cerebral aneurysms and intracranial atherosclerotic disease. The Enterprise stent (Cordis Neurovascular, Miami Lakes, FL, USA), the Neuroform system (Stryker, Natick, MA, USA), and the Leo stent (Balt Extrusion, Montmorency, France) are devices introduced for stent-assisted coiling of wide-neck aneurysms. The latter stent is not marketed in the United States. The Wingspan system (Stryker, Natick, MA, USA) was approved for treatment of intracranial atherosclerosis. Both the Neuroform and Wingspan stents have an open-cell design, whereas the Enterprise and Leo stents are closed-cell design (Nogueira et al., 2009b). The closedcell design allows resheathing of the stent after partial deployment (70\% for Enterprise and 90\% for Leo; Lubicz et al., 2006; Peluso et al., 2008).

These devices have been used off-label in the treatment of AIS. The concept of flow restoration without clot removal has gained attention as other recanalization approaches that focus their strategy in thrombectomy have failed.

Fitzsimmons and Nelson reported one of the first cases of cerebral revascularization with deployment of a SES (Fitzsimmons et al., 2006). A Neuroform stent was deployed in an occluded left middle cerebral artery after the IA infusion of a glycoprotein (GP) IIb/IIIa inhibitor failed to recanalize the vessel. Multiple reports have followed (Table 1), especially from the group lead by Levy et al. (2007a) who have pioneered the use of SES in the treatment of AIS. In 2007 they reported a $100 \%$ successful deployment of SES (16 Neuroform and 3 Wingspan stents) in the target occlusion, achieving a thrombolysis-in-cerebral-infarction score (TICI)/TIMI 2/3 recanalization in $79 \%$ of lesions. Four patients $(22 \%)$ had a modified Rankin Scale $(\mathrm{mRS}) \leq 3$ at 3 months and two patients $(11 \%)$ suffered symptomatic intracerebral hemorrhage (sICH).

Most of the studies published to date have been retrospective single-center reports with sample sizes ranging between 9 and 20 patients (Zaidat et al., 2008; Brekenfeld et al., 2009; Mocco et al., 2010; Suh et al., 2010; Linfante et al., 2011). Although these cohorts are small, recanalization rates of 92 and 100\% have been reported in cases where other thrombectomy devices have failed (Brekenfeld et al., 2009; Mocco et al., 2010; Linfante et al., 2011). The stent-assisted recanalization in AIS (SARIS) study, is a prospective trial that recently reported preliminary data in the treatment of 20 patients with AIS. TIMI $2 / 3$ was achieved in $100 \%$ of cases with a $5 \%$ rate of sICH (Levy et al., 2009). A 6-month followup of the SARIS trial found $\mathrm{mRS} \leq 2$ in $55 \%$ of patients $(n=11)$ with a mortality rate of $35 \%(n=7)$. None of the patients had instent restenosis and all had TIMI-3 flow in angiographic follow-up (Levy et al., 2011).

We recently reported our experience in the use of SES for treatment of AIS refractory to other recanalization treatments (Linfante et al., 2011). We reviewed our database of stroke patients treated between August 2008 and September 2010. A total of 19 patients with AIS underwent stenting achieving a 95\% recanalization rate (Figures 1-3). $42 \%$ of patients achieved a $\mathrm{mRS} \leq 2$. We did not experience any technical complications, however, due to the routine IA administration of GP IIb/IIIa inhibitors before stent deployment we encountered a higher rate of $\mathrm{sICH}(16 \%)$. 16 patients in our series received concomitant administration of intravenous (IV) and/or IA tissue plasminogen activator (tPA).

Table 1 | Larger series with self-expandable stents in the treatment of acute ischemic stroke.

\begin{tabular}{|c|c|c|c|c|c|c|c|c|}
\hline & Study & Patients & $\begin{array}{l}\text { Stent, } \\
n \text { (type) }\end{array}$ & $\begin{array}{l}\text { Recanalization, } \\
(\%)\end{array}$ & $\begin{array}{l}\text { Antiplatelets, } \\
n(\%)\end{array}$ & $\begin{array}{l}\text { IV tPA, } \\
n(\%)\end{array}$ & $\begin{array}{l}\text { sICH, } \\
n(\%)\end{array}$ & $\begin{array}{l}\text { Clinical } \\
\text { outcome (\%) }\end{array}$ \\
\hline SES: & Levy et al. (2007a) & 18 & $16(N), 3(\mathrm{~W})$ & 79 (TICl/TIMI 2/3) & GP $10(56)$ & $5(28)$ & $2(11)$ & $22(\mathrm{mRS} \leq 3$ at $3 \mathrm{M})$ \\
\hline \multirow[t]{4}{*}{$\begin{array}{l}\text { retrospective } \\
\text { series }\end{array}$} & Zaidat et al. (2008) & 9 & $4(N), 5(W)$ & 89 (TICl/TIMI 2/3) & GP 6 (67) & $1(11)$ & None & $\begin{array}{l}67 \text { (mRS } \leq 2 \text { at mean } \\
\text { follow-up } 12.5 \mathrm{M})\end{array}$ \\
\hline & Brekenfeld et al. (2009) & 12 & $14(\mathrm{~W})$ & 92 (TIMI 2/3) & GP 1 (8) & None & None & $35(\mathrm{mRS} \leq 2$ at $3 \mathrm{M})$ \\
\hline & Mocco et al. (2010) & 20 & $20(E)$ & 100 (TIMI 2/3) & GP $11(55)$ & $10(50)$ & $2(10)$ & 75 (NIHSS $\downarrow \geq 4)$ \\
\hline & Linfante et al. (2011) & 19 & $13(W), 6(E)$ & 95 (TIMI 2/3) & GP 19 (100) & $8(42)$ & $3(16)$ & $\begin{array}{l}42(\mathrm{mRS} \leq 2 \text { at } 1 \mathrm{M}) \\
63(\mathrm{mRS} \leq 3 \text { at } 1 \mathrm{M})\end{array}$ \\
\hline SARIS $^{+}$ & Levy et al. (2009) & 20 & $17(\mathrm{~W}), 2(\mathrm{E})$ & 100 (TIMI 2/3) & None & $3(15)$ & $1(5)$ & $60(\mathrm{mRS} \leq 3$ at $2 \mathrm{M})$ \\
\hline Stent retriever: & Roth et al. (2010) & 22 & $22(S)$ & $91(\mathrm{TICl} 2 \mathrm{a} / \mathrm{b} / 3)$ & IV ASA $6(27)^{*}$ & $13(59)$ & $2(9)$ & $50(\mathrm{mRS} \leq 2$ at $3 \mathrm{M})$ \\
\hline retrospective & Castano et al. (2010) & 20 & $20(S)$ & $90(\mathrm{TICl} 2 / 3)$ & None & $10(50)$ & $2(10)$ & $45(\mathrm{mRS} \leq 2$ at $3 \mathrm{M})$ \\
\hline \multirow[t]{2}{*}{ series } & Machi et al. (2011) & 56 & $56(S)$ & 89 (TICl 2b/3) & None & NA & $1(1.8)$ & $\begin{array}{l}46 \text { ( } \mathrm{mRS} \leq 2 \text { at } \\
\text { discharge) }\end{array}$ \\
\hline & Mpotsaris et al. (2011) & 26 & $26(S)$ & 88 (TIMI 2/3) & None & $19(73)$ & NA & $\begin{array}{l}38 \text { (mRS } \leq 2 \text { at } \\
\text { discharge) }\end{array}$ \\
\hline
\end{tabular}

+ SARIS is the only single-arm prospective study of primary stenting in stroke approved by the Food and Drug Administration.

*Intravenous aspirin was administered in six patients with tandem internal carotid artery occlusions/stenosis whom required stenting.

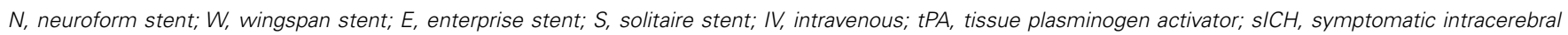

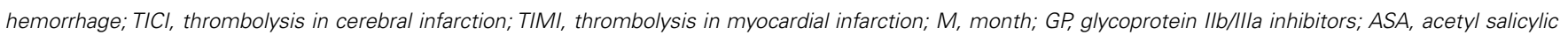
acid; NA, not available; mRS, Modified Rankin Scale; NIHSS, National Institute of Health Stroke Scale; SARIS, stent-assisted recanalization for acute ischemic stroke; SES, self-expandable stents. 


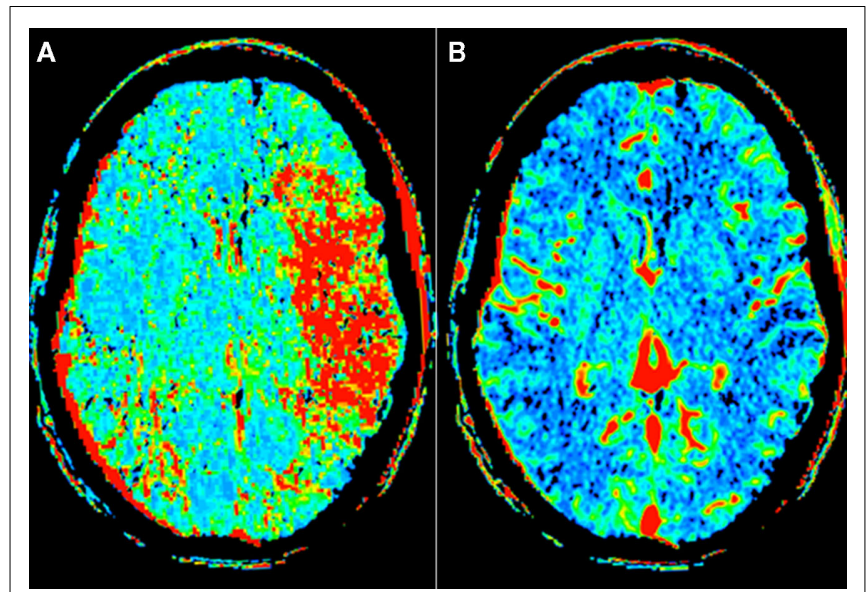

FIGURE 1 | Computed tomography perfusion (CTP) of a 53-year-old man who presented with a National Institute of Health Stroke Scale of $\mathbf{2 0}$ approximately $\mathbf{2} \mathbf{h}$ after symptom onset. The perfusion map demonstrates a mismatch with increased mean transient time (A) and normal blood volume (B) in the left middle cerebral artery (MCA) territory.

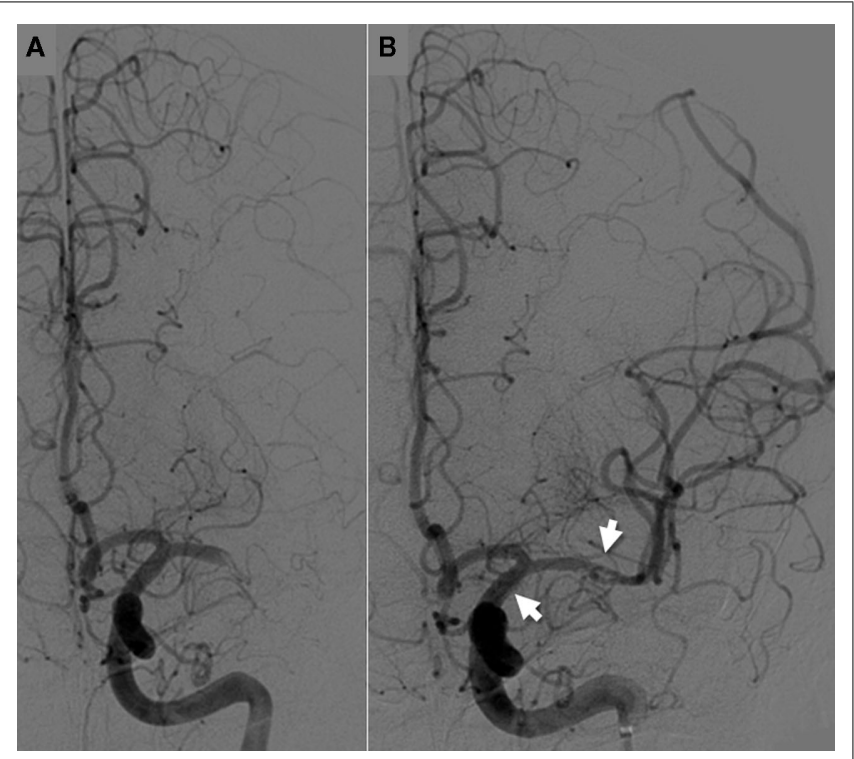

FIGURE 2 | Cerebral angiogram shows a left MCA-M1 occlusion (A), which was successfully recanalized with deployment of a self-expandable stent (B). Intraarterial infusion of tissue plasminogen activator (25 MG) and thrombectomy with the Concentric Merci Retriever failed to recanalize the occlusion. Arrows demonstrate the proximal and distal ends of the stent.

The cumulative experience of these reports has let to the following observations:

1. Stenting in AIS appears to be technically feasible as reported in the $100 \%$ successful deployment rate of different studies (Brekenfeld et al., 2007; Levy et al., 2007a, 2009; Mocco et al., 2010; Linfante et al., 2011). Zaidat et al. (2008) reported one technical failure when a Wingspan stent could not track beyond

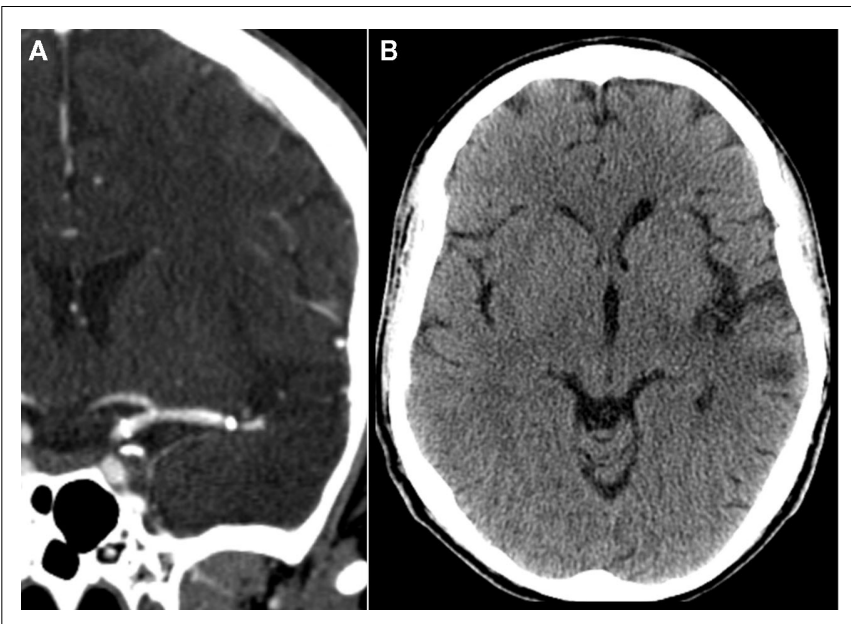

FIGURE 3 | Computed tomography (CT) angiography demonstrating patency of the stent in a 6-month follow-up (A). Non-contrast CT demonstrates a small left MCA territory infarct (B).

the middle cerebral artery/internal carotid artery junction and was deployed in the proximal clot.

2. Acute in-stent thrombosis is rare and different treatment strategies may be used to achieve stent recanalization: IA administration of GP IIb/IIIa inhibitors (Zaidat et al., 2008; Brekenfeld et al., 2009; Suh et al., 2010), angioplasty (Zaidat et al., 2008), and stent resheathing (the Enterprise system allows recapture after partial deployment; Suh et al., 2010).

3. Enterprise stents appear to have better navigability than the Wingspan and Neuroform stents, especially in AIS patients who generally have a tortuous anatomy with atherosclerotic changes. Levy et al. (2009) used Enterprise stents in two cases where the Wingspan system could not be advanced due to severe vessel tortuosity. In our experience, Enterprise stents were successfully deployed in two cases where cerebrovasculature tortuosity limited the use of Wingspan (Linfante et al., 2011). Moreover, we were able to deploy an Enterprise stent in a right $\mathrm{M} 1$ occlusion through the contralateral left internal carotid artery and across the anterior communicating artery due to occlusion of the proximal right common carotid artery. The Enterprise catheter-based delivery system appears to have improved navigability and ease of deployment as Mocco et al. (2010) reported as well in their cohort of 20 patients with AIS.

4. Despite concerns that SES would not have the enough radial force to recanalize occluded arteries, angiographic outcomes have improved since the first series published by Levy et al. (2009) achieving TIMI 2/3 flow in more than $90 \%$ of lesions (Brekenfeld et al., 2009; Levy et al., 2009; Mocco et al., 2010; Linfante et al., 2011).

5. Antiplatelet agents such as aspirin and clopidogrel or GP IIb/IIIa inhibitors should be administered prior to stent deployment to avoid acute in-stent thrombosis (Zaidat et al., 2008; Brekenfeld et al., 2009; Suh et al., 2010). However, this may lead to sICH if thrombolytic agents have been previously administered (Linfante et al., 2011). 
In summary, SES like the Enterprise, Neuroform, and Wingspan systems appear to have better navigability, trigger less vasospasm, and side-branch occlusions than balloon-mounted stents (Levy et al., 2006b). Additionally, SES do not require balloon inflation in vessels with an unknown diameter. Unfortunately, SES can only be used in $\geq 2-\mathrm{mm}$ vessels and chemical thrombolysis may be needed to achieve complete distal recanalization, increasing the risk of sICH.

A large multicenter retrospective study that included 1122 patients with AIS determined that patients treated with multimodal therapy had significant higher TIMI 2/3 recanalization rates $(74 \%)$ compared with pharmacological therapy only (61\%) or mechanical treatment alone (63\%; Gupta et al., 2011). Among individual treatment modalities, stent deployment or IA thrombolysis increased the chance of recanalization.

\section{DRAWBACKS OF STENTS IN AIS}

The use of SES in the AIS has potential drawbacks:

1. Permanent deployment of SES in the setting of AIS requires platelet inhibition to reduce the possibility of in-stent thrombosis. Intra-procedural administration of GP IIb/IIIa inhibitors or inhibitors of platelet function in AIS may in turn increase the risk of hemorrhagic transformation. This is particularly worrisome in patient who have already been treated with IV and/or IA thrombolytics (Linfante et al., 2011).

2. Stent placement in AIS is a permanent implant to resolve a temporary occlusion that may be caused by an embolus.

3. Stent deployment may result in delayed in-stent stenosis (Levy et al., 2007b).

To eliminate these potential pitfalls, retrievable stents, also known as "stentrievers," were introduced. A stentriever can act as a stent and recanalize the occluded lumen. It can then be retrieved so that it does not become a permanent implant. While retrieved, it can function as thrombectomy device as well.

\section{RETRIEVABLE-THROMBECTOMY STENTS}

Mayer et al. (2002) reported their experience in the treatment of AIS with a self-expandable basket that had a stent configuration and was used to recanalize a basilar artery. The device, named Neuronet (Guidant, Menlo Park, CA, USA), probably constitutes an earlier version of a retrievable stent. Unfortunately, the device was not commercialized.

In vitro and animal testing with the Enterprise stent showed successful thrombectomy once the stent was resheathed after partial deployment (Wakhloo and Gounis, 2008). Kelly et al. (2008) reported successful recanalization of a right $\mathrm{M} 1$ occlusion with an Enterprise stent after failed IA thrombolysis. The stent was deployed for $20 \mathrm{~min}$ and then reconstrained and removed. This report is the first account of a SES that was retrieved after achieving recanalization in AIS. Hauck et al. (2009) used the same approach for recanalization of a vertebrobasilar occlusion. A 4.5- $\mathrm{mm} \times 37$ $\mathrm{mm}$ Enterprise stent was deployed for $18 \mathrm{~min}$ and then recaptured achieving a good angiographic result.

The Solitaire revascularization device is a stent based thrombectomy system with a closed-cell design specifically designed to operate as a "retrievable" stent. The device has a dual purpose: temporal intracranial bypass with flow restoration through the occluded arterial segment; and clot retriever after trapping the thrombus into its cells. Current reports with this device come from different European centers since the device is not currently approved in the United States. Castano et al. (2010) reported their experience in the treatment of 20 patients with AIS and large vessel occlusion in the anterior circulation. TICI $2 \mathrm{~b} / 3$ was achieved in $90 \%$ of treated vessels and no procedural complications were reported. sICH occurred in $10 \%$ of patients and $45 \%$ achieved a $\mathrm{mRS} \leq 2$ at 3 months. The device used in this study is the Solitaire $\mathrm{AB}$ stent, initially designed as an aneurysm neck bridging stent. The device was deployed for 1 or $2 \mathrm{~min}$ before retrieving it to perform embolectomy. Recanalization required in average 1.4 passes. The successful off-label use of this stent prompted the creation of the Solitaire FR device with minimal modifications from the AB version, and specifically designed for treatment of AIS.

Machi et al. (2011) achieved successful recanalization in 50 out of 56 patients $(89 \%)$ treated with the Solitaire FR device. Procedure related complications occurred in $9 \%$ of patients and $46 \%$ achieved a $\mathrm{mRS} \leq 2$ at discharge. The mean number of passes required per procedure was 2 (1-5 range). The device was positioned across the area of occlusion for 3-7 min and then gently recovered into the guide catheter. Vasospasm during retrieval of the fully deployed stent was a common phenomenon, two patients had asymptomatic SAH and one patient sICH.

Similarly, Roth et al. (2010) treated 22 patients with AIS and achieved TICI $2 \mathrm{a} / \mathrm{b}$ and 3 flow in $91 \%$ of patients. Two sICH occurred and $50 \%$ of patients achieved a $\mathrm{mRS} \leq 2$ at 90 days. Vasospasm after thrombectomy was noticed in three patients and no device-related complications were reported.

Investigators of the rescue, combined, and stand-alone thrombectomy (RECOST) study, achieved TICI 3 flow in $84 \%$ of patients with AIS treated with the Solitaire FR/AB device (Costalat et al., 2011). The aim of this study was to evaluate and appraise the timing, safety and efficacy of an integrated stroke management protocol. At 3 months, $54 \%$ of patients achieved a $\mathrm{mRS} \leq 2$ and $2 \%$ had sICH. The device was deployed for 2-7 min in the target occlusion before thrombectomy.

The Trevo System is a non-deployable stent-like device currently being used in Europe and Canada. The soft body of the device allows easy navigation through tortuous vessels and its distal closed-end is intended to prevent vessel perforation. The device can be used in vessels ranging from 1.5 to $3.5 \mathrm{~mm}$ in diameter. The orientation of the stent struts has the broader portion of the struts facing the vessel lumen in order to optimized thrombus incorporation, opposite to the design of stents used to treat intracranial aneurysms of intracranial atherosclerosis (Nogueira et al., 2011).

These results appear promising as the devices continue to evolve, become more operator friendly and patient outcomes improve. Three studies are underway in the United States and Europe to test retrievable stents in the treatment of AIS. The Solitaire FR with the Intention for Thrombectomy (SWIFT) study which is ongoing (recruitment completed) and will compare Solitaire FR with the Merci retriever in 200 patients. The Trial and Cost Effectiveness Evaluation of IA Thrombectomy in AIS (THRACE) study will compare IV thrombolysis with thrombectomy procedures using the Merci retriever, Penumbra 
system, Catch device (Balt Extrusion, Montmorency, France), and the Solitaire FB stent in 480 patients. The Thrombectomy Revascularization of Large Vessel Occlusions (TREVO 2) study was recently started in the United States and will compare the Trevo system versus the Merci retriever in the treatment of AIS. Approximately 178 patients would be enrolled in the study.

\section{TECHNICAL BENEFITS AND LIMITATIONS OF STENTING IN AIS}

Deployment of the stent at the occlusion site with flow restoration to the area at risk may increase tissue savage. Experimental research in animal models has shown that intermittent restoration of flow to the infarct area can reduce the final infarct size (Zhao, 2009). The stent bypasses the area of occlusion restoring flow to more distal branches.

Once the stent is open, the clot gets trapped between the stent and the vessel wall. This is an important concept and differs from conventional thrombectomy approaches aimed to extract the clot. This latter strategy is more laborious and time consuming, delaying recanalization. Once the stent expands through the occlusion, thrombus material may be pushed into perforating arteries. This phenomenon described as "snow-plowing," (Levy and Chaturvedi, 2006) may explain strokes in perforator territories once the main artery has been recanalized and may be one of the drawbacks of this technique.

A technical aspect of thrombectomy with the retrievable stents is the deployment time. It is advised to unsheathe the device for at least 2 min to allow full expansion of the nitinol struts through the thrombus, this facilitates clot entrapment and later on thrombectomy. Deployment times have varied between 1 and 7 min among different studies (Castano et al., 2010; Costalat et al., 2011; Machi et al., 2011).

Withdrawing an unfolded stent to perform thrombectomy increases the risk of intimal injury to the vessel wall. Preliminary

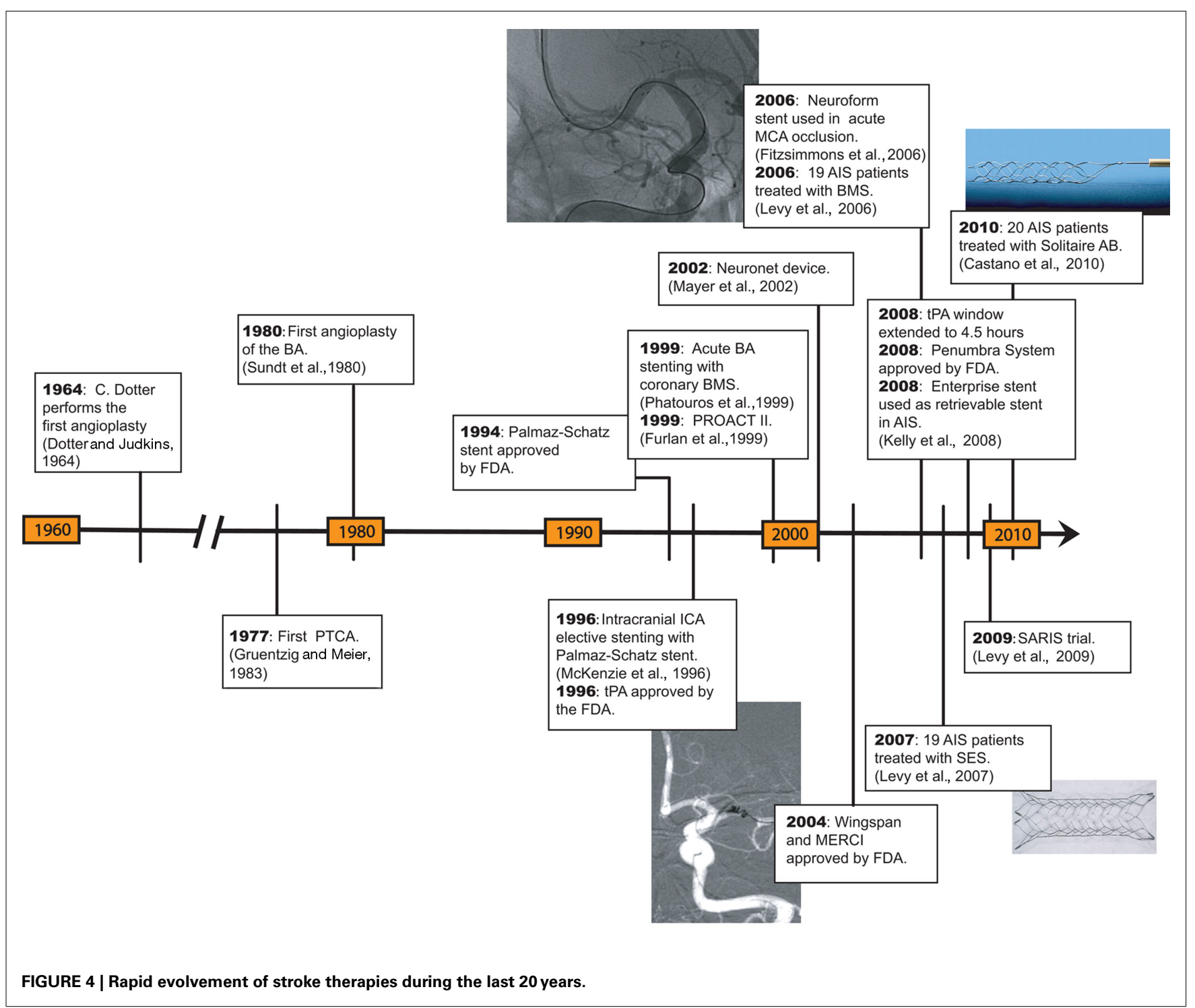


animal studies with the Solitaire device in swine were remarkable for vasospasm which resolved without sequelae (Jahan, 2010). Microscopic examination of the vessels were the device was deployed showed mild intimal thickening leading to $1-5 \%$ narrowing, which was not visualized in angiography. Vasospasm and SAH have been described in clinical studies after thrombectomy with the Solitaire device (Roth et al., 2010; Machi et al., 2011). Histopathological analysis of swine external carotid branches after thrombectomy with the Trevo stent, showed severe disruption of the intimae but there was no hemorrhage nor evidence of transmural dissection (Nogueira et al., 2011).

A theoretical advantage of retrievable stents over other conventional thrombectomy devices is that "stentrievers" gradually expand as they are pulled proximally into the guide catheter. Indeed, the inherent radial force of the stentriever theoretically traps the clot against the vessel wall during thrombectomy. This may prevent the retrieved thrombi from dislodging from the stentriever and embolizing distally (Nogueira et al., 2011).

If a suboptimal angiographic result is achieved after thrombectomy, the Solitaire device can be reposition and permanently deployed as an stent ( $\mathrm{AB}$ version). The system allows detachment of the stent-like a coil. This application may be useful in recanalization of atherothrombotic lesions or if the stent cannot be recaptured.

\section{REFERENCES}

Brekenfeld, C., Remonda, L., Nedeltchev, K., Arnold, M., Mattle, H. P., Fischer, U., Kappeler, L., and Schroth, G. (2007). Symptomatic intracranial haemorrhage after intra-arterial thrombolysis in acute ischaemic stroke: assessment of 294 patients treated with urokinase. $J$. Neurol. Neurosurg. Psychiatry 78, 280-285.

Brekenfeld, C., Schroth, G., Mattle, H. P., Do, D. D., Remonda, L., Mordasini, P., Arnold, M., Nedeltchev, K., Meier, N., and Gralla, J. (2009). Stent placement in acute cerebral artery occlusion: use of a selfexpandable intracranial stent for acute stroke treatment. Stroke 40, 847-852.

Castano, C., Dorado, L., Guerrero, C., Millan, M., Gomis, M., Perez De La Ossa, N., Castellanos, M., Garcia, M. R., Domenech, S., and Davalos, A. (2010). Mechanical thrombectomy with the Solitaire AB device in large artery occlusions of the anterior circulation: a pilot study. Stroke 41, 1836-1840.

Chiam, P. T., Samuelson, R. M., Mocco, J., Hanel, R. A., Siddiqui, A. H., Hopkins, L. N., and Levy, E. I. (2008). Navigability trumps all: stenting of acute middle cerebral artery occlusions with a new self-expandable stent. AJNR Am. J. Neuroradiol. 29, 1956-1958.

Costalat, V., Machi, P., Lobotesis, K., Maldonado, I., Vendrell, J. F., Riquelme, C., Mourand, I., Milhaud, D., Heroum, C., Perrigault, P. F., Arquizan, C., and Bonafe, A. (2011). Rescue, combined, and stand-alone thrombectomy in the management of large vessel occlusion stroke using the solitaire device: a prospective 50-patient single-center study: timing, safety, and efficacy. Stroke 42, 1929-1935.

Dotter, C. T., and Judkins, M. P. (1964). Transluminal treatment of arteriosclerotic obstruction. Description of a new technic and a preliminary report of its application. Circulation 30, 654-670.

Fitzsimmons, B. F., Becske, T., and Nelson, P. K. (2006). Rapid stentsupported revascularization in acute ischemic stroke. AJNR Am. J. Neuroradiol. 27, 1132-1134.

Flint, A. C., Duckwiler, G. R., Budzik, R. F., Liebeskind, D. S., and Smith, W. S. (2007). Mechanical thrombectomy of intracranial internal carotid occlusion: pooled results of the MERCI and Multi MERCI Part I trials. Stroke 38, 1274-1280.

Furlan, A., Higashida, R., Wechsler, L., Gent, M., Rowley, H., Kase, C., Pessin, M., Ahuja, A., Callahan, F.,

\section{CONCLUSION}

Stents initially conceived for aneurysm remodeling (Enterprise and Neuroform stents) and treatment of intracranial atherosclerosis (Wingspan stent) have paved the way for new therapeutic approaches in AIS (Figure 4). SES are easier to deliver than balloon-mounted stents and are thought to carry a lower risk of vascular injury (Chiam et al., 2008; Samaniego et al., 2009). However, these devices usually require loading doses of antiplatelet medications before permanent stent deployment. Moreover, dual antiplatelet therapy is continued for at least the initial 3 months after the procedure. This raises safety concerns in patients who have received IV or IA thrombolytics. In our experience, routine administration of IA GP IIb/IIIa inhibitors before stent deployment despite previous IV and/or IA tPA administration carries a higher risk of sICH (Linfante et al., 2011).

Retrievable stents appear to ease this technical issue, once deployed they bypass the area of occlusion providing flow to the ischemic area at risk. The operator may then recapture the stent or perform a thrombectomy with the stent unsheathed. However, complications like vasospasm and intimal injury with vessel rupture have been reported with this approach.

In summary, deployment of SES in AIS may be a safe alternative for recanalization of large intracranial vessels in patients in whom other current available devices failed. Newer stent-based technologies like retrievable stents may add even more tools to the treatment of AIS.

Clark, W. M., Silver, F., and Rivera, F. (1999). Intra-arterial prourokinase for acute ischemic stroke. The PROACT II study: a randomized controlled trial. Prolyse in acute cerebral thromboembolism. JAMA 282, 2003-2011.

Gounis, M. J., Deleo, M. J. III, and Wakhloo, A. K. (2010). Advances in interventional neuroradiology. Stroke 41, e81-e87.

Gruentzig, A. R., and Meier, B. (1983). Percutaneous transluminal coronary angioplasty. The first five years and the future. Int. J. Cardiol. 2, 319-323.

Gupta, R., Schumacher, H. C., Mangla, S., Meyers, P. M., Duong, H., Khandji, A. G., Marshall, R. S., Mohr, J. P., and Pile-Spellman, J. (2003). Urgent endovascular revascularization for symptomatic intracranial atherosclerotic stenosis. Neurology 61, 1729-1735.

Gupta, R., Tayal, A. H., Levy, E. I., Cheng-Ching, E., Rai, A., Liebeskind, D. S., Yoo, A. J., Hsu, D. P., Rymer, M. M., Zaidat, O. O., Lin, R., Natarajan, S. K., Nogueira, R. G., Nanda, A., Tian, M., Hao, Q., Abou-Chebl, A., Kalia, J. S., Nguyen, T. N., Chen, M., and Jovin, T. G. (2011). Intra-arterial thrombolysis or stent placement during endovascular treatment for acute ischemic stroke leads to the highest recanalization rate: results of a multicenter retrospective study. Neurosurgery 68 , 1618-1623.

Hauck, E. F., Mocco, J., Snyder, K. V., and Levy, E. I. (2009). Temporary endovascular bypass: a novel treatment for acute stroke. AJNR Am. J. Neuroradiol. 30, 1532-1533.

IMS Study Investigators. (2004). Combined intravenous and intra-arterial recanalization for acute ischemic stroke: the Interventional Management of Stroke Study. Stroke 35, 904-911.

Jahan, R. (2010). Solitaire flowrestoration device for treatment of acute ischemic stroke: safety and recanalization efficacy study in a swine vessel occlusion model. AJNR Am. J. Neuroradiol. 31, 1938-1943.

Kelly, M. E., Furlan, A. J., and Fiorella, D. (2008). Recanalization of an acute middle cerebral artery occlusion using a self-expanding, reconstrainable, intracranial microstent as a temporary endovascular bypass. Stroke 39 , 1770-1773.

Levy, E. I., and Chaturvedi, S. (2006). Perforator stroke following intracranial stenting: a sacrifice for the greater good? Neurology 66, 1803-1804. 
Levy, E. I., Ecker, R. D., Horowitz, M. B., Gupta, R., Hanel, R. A., Sauvageau, E., Jovin, T. G., Guterman, L. R., and Hopkins, L. N. (2006a). Stentassisted intracranial recanalization for acute stroke: early results. $\mathrm{Neu}$ rosurgery 58, 458-463; discussion 458-463.

Levy, E. I., Sauvageau, E., Hanel, R. A., Parikh, R., and Hopkins, L. N. (2006b). Self-expanding versus balloon-mounted stents for vessel recanalization following embolic occlusion in the canine model: technical feasibility study. AJNR Am. J. Neuroradiol. 27, 2069-2072.

Levy, E. I., Mehta, R., Gupta, R., Hanel, R. A., Chamczuk, A. J., Fiorella, D., Woo, H. H., Albuquerque, F. C., Jovin, T. G., Horowitz, M. B., and Hopkins, L. N. (2007a). Self-expanding stents for recanalization of acute cerebrovascular occlusions. AJNR Am. J. Neuroradiol. 28, 816-822.

Levy, E. I., Turk, A. S., Albuquerque, F. C., Niemann, D. B., Aagaard-Kienitz, B., Pride, L., Purdy, P., Welch, B., Woo, H., Rasmussen, P. A., Hopkins, L. N., Masaryk, T. J., Mcdougall, C. G., and Fiorella, D. J. (2007b). Wingspan in-stent restenosis and thrombosis: incidence, clinical presentation, and management. Neurosurgery 61, 644-650; discussion 650-641.

Levy, E. I., Rahman, M., Khalessi, A. A., Beyer, P. T., Natarajan, S. K., Hartney, M. L., Fiorella, D. J., Hopkins, L. N., Siddiqui, A. H., and Mocco, J. (2011). Midterm clinical and angiographic follow up for the first FDA-approved prospective, Single-arm Trial of Primary Stenting for Stroke: SARIS (stentassisted recanalization for acute ischemic stroke). Neurosurgery 69, 915-920.

Levy, E. I., Siddiqui, A. H., Crumlish, A., Snyder, K. V., Hauck, E. F., Fiorella, D. J., Hopkins, L. N., and Mocco, J. (2009). First Food and Drug Administration-approved prospective trial of primary intracranial stenting for acute stroke: SARIS (stent-assisted recanalization in acute ischemic stroke). Stroke 40, 3552-3556.

Linfante, I., Samaniego, E. A., Geisbusch, P., and Dabus, G. (2011).
Self-expandable stents in the treatment of acute ischemic stroke refractory to current thrombectomy devices. Stroke 42, 2636-2638.

Lubicz, B., Leclerc, X., Levivier, M., Brotchi, J., Pruvo, J. P., Lejeune, J. P., and Baleriaux, D. (2006). Retractable self-expandable stent for endovascular treatment of widenecked intracranial aneurysms: preliminary experience. Neurosurgery 58, 451-457; discussion 451-457.

Machi, P., Costalat, V., Lobotesis, K., Lima Maldonado, I., Vendrell, J. F., Riquelme, C., and Bonafe, A. (2011). Solitaire FR thrombectomy system: immediate results in 56 consecutive acute ischemic stroke patients. J. Neurointerv. Surg. doi: 10.1136/jnis.2010.004051

Mayer, T. E., Hamann, G. F., and Brueckmann, H. (2002). Mechanical extraction of a basilar-artery embolus with the use of flow reversal and a microbasket. N. Engl. J. Med. 347, 769-770.

Mckenzie, J. D., Wallace, R. C., Dean, B. L., Flom, R. A., and Khayata, M. H. (1996). Preliminary results of intracranial angioplasty for vascular stenosis caused by atherosclerosis and vasculitis. AJNR Am. J. Neuroradiol. 17, 263-268.

Mocco, J., Hanel, R. A., Sharma, J., Hauck, E. F., Snyder, K. V., Natarajan, S. K., Linfante, I., Siddiqui, A. H., Hopkins, L. N., Boulos, A. S., and Levy, E. I. (2010). Use of a vascular reconstruction device to salvage acute ischemic occlusions refractory to traditional endovascular recanalization methods. J. Neurosurg. 112, 557-562.

Mpotsaris, A., Bussmeyer, M., Loehr, C., Oelerich, M., Buchner, H., and Weber, W. (2011). Mechanical thrombectomy in severe acute stroke: preliminary results of the Solitaire stent. J. Neurol. Neurosurg. Psychiatr. doi: 10.1136/jnnp.2010.225573

Nogueira, R. G., Levy, E. I., Gounis, M., and Siddiqui, A. H. (2011). The Trevo device: preclinical data of a novel stroke thrombectomy device in two different animal models of arterial thrombo-occlusive disease. J. Neurointerv. Surg. doi: 10.1136/neurintsurg-2011-010053
Nogueira, R. G., Liebeskind, D. S., Sung, G., Duckwiler, G., and Smith, W. S. (2009a). Predictors of good clinical outcomes, mortality, and successful revascularization in patients with acute ischemic stroke undergoing thrombectomy: pooled analysis of the mechanical embolus removal in cerebral ischemia (MERCI) and Multi MERCI Trials. Stroke 40, 3777-3783.

Nogueira, R. G., Schwamm, L. H., and Hirsch, J. A. (2009b). Endovascular approaches to acute stroke, part 1: drugs, devices, and data. AJNR Am. J. Neuroradiol. 30, 649-661.

Peluso, J. P., Van Rooij, W. J., Sluzewski, M., and Beute, G. N. (2008). A new self-expandable nitinol stent for the treatment of wide-neck aneurysms: initial clinical experience. AJNR Am. J. Neuroradiol. 29, 1405-1408.

Penumbra Pivotal Stroke Trial Investigators. (2009). The penumbra pivotal stroke trial: safety and effectiveness of a new generation of mechanical devices for clot removal in intracranial large vessel occlusive disease. Stroke 40, 2761-2768.

Phatouros, C. C., Higashida, R. T. Malek, A. M., Smith, W. S., Mully, T. W., Dearmond, S. J., Dowd, C. F., and Halbach, V. V. (1999). Endovascular stenting of an acutely thrombosed basilar artery: technical case report and review of the literature. Neurosurgery 44, 667-673.

Roth, C., Papanagiotou, P., Behnke, S. Walter, S., Haass, A., Becker, C., Fassbender, K., Politi, M., Korner, H., Romann, M. S., and Reith, W. (2010). Stent-assisted mechanical recanalization for treatment of acute intracerebral artery occlusions. Stroke 41, 2559-2567.

Samaniego, E. A., Hetzel, S. Thirunarayanan, S., AagaardKienitz, B., Turk, A. S., and Levine, R. (2009). Outcome of symptomatic intracranial atherosclerotic disease. Stroke 40, 2983-2987.

Smith, W. S., Sung, G., Starkman, S. Saver, J. L., Kidwell, C. S., Gobin, Y. P., Lutsep, H. L., Nesbit, G. M., Grobelny, T., Rymer, M. M., Silverman, I. E., Higashida, R. T., Budzik, R. F., and Marks, M. P. (2005). Safety and efficacy of mechanical embolectomy in acute ischemic stroke: results of the MERCI trial. Stroke 36, 1432-1438.
Suh, S. H., Kim, B. M., Roh, H. G. Lee, K. Y., Park, S. I., Kim, D. I., Kim, D. J., Nam, H. S., and Choi, H. S. (2010). Self-expanding stent for recanalization of acute embolic or dissecting intracranial artery occlusion. AJNR Am. J. Neuroradiol. 31, 459-463.

Sundt, T. M. Jr., Smith, H. C., Campbell, J. K., Vlietstra, R. E., Cucchiara, R. F., and Stanson, A. W. (1980). Transluminal angioplasty for basilar artery stenosis. Mayo Clin. Proc. 55, 673-680.

Wakhloo, A. K., and Gounis, M. J. (2008). Retrievable closed cell intracranial stent for foreign body and clot removal. Neurosurgery 62, ONS390-ONS393; discussion ONS393-ONS394.

Zaidat, O. O., Wolfe, T., Hussain, S. I., Lynch, J. R., Gupta, R., Delap, J., Torbey, M. T., and Fitzsimmons, B. F. (2008). Interventional acute ischemic stroke therapy with intracranial self-expanding stent. Stroke 39, 2392-2395.

Zhao, H. (2009). Ischemic postconditioning as a novel avenue to protect against brain injury after stroke. J. Cereb. Blood Flow Metab. 29, 873-885.

Conflict of Interest Statement: Dr. Linfante is a consultant for Codman Neurovascular and Concentric Medical. Dr. Dabus is consultant for Codman Neurovascular and shareholder for Surpass Medical. Dr. Samaniego and Dabus do not report any conflict of interest.

Received: 16 September 2011; accepted: 17 November 2011; published online: 09 December 2011.

Citation: Samaniego EA, Dabus G and Linfante I (2011) Stenting in the treatment of acute ischemic stroke: literature review. Front. Neur. 2:76. doi: 10.3389/fneur.2011.00076

This article was submitted to Frontiers in Endovascular and Interventional Neurology, a specialty of Frontiers in Neurology. Copyright (C) 2011 Samaniego, Dabus and Linfante. This is an open-access article distributed under the terms of the Creative Commons Attribution Non Commercial License, which permits noncommercial use, distribution, and reproduction in other forums, provided the original authors and source are credited. 